\title{
Characterization of Colletotrichum gloeosporioides Isolates from Ornamental Lupines in Connecticut
}

\author{
Wade H. Elmer, Associate Plant Pathologist, The Connecticut Agricultural Experiment Station, New Haven 06405; \\ Huaan A. Yang, Cooperative Research Centre for Legumes in Mediterranean Agriculture, The University of \\ Western Australia, Nedlands WA 6907 Australia; and Mark W. Sweetingham, Agriculture Western Australia, \\ Locked Bag No. 4, Bentley Delivery Centre, WA 6983 Australia
}

\begin{abstract}
Elmer, W. H., Yang, H. A., and Sweetingham, M. W. 2001. Characterization of Colletotrichum gloeosporioides isolates from ornamental lupines in Connecticut. Plant Dis. 85:216-219.

Twenty-six isolates of Colletotrichum gloeosporioides were isolated from diseased ornamental lupines (Lupinus spp. 'Russell Hybrids') in seven different nurseries in Connecticut from 1996 to 1998. Three isolates from New Hampshire, New York, and Utah were also included. All isolates identified were pathogenic on lupine and vegetatively compatible with each other. Representative isolates were compared to lupine isolates from Quebec, Canada and France (COL-1 group), and from Australia and France (COL-2 group). Both groups are responsible for causing anthracnose of ornamental and forage Lupinus spp. in these countries. The Connecticut isolates were vegetatively compatible with the isolates in the COL-2 group and had random amplified polymorphic DNA profiles consistent with isolates in the COL-2 group. Isolates in the COL-1 group were vegetatively compatible only with each other and had random amplified polymorphic DNA profiles that differed from the COL-2 group. Isolates in both COL-1 and COL-2 were sensitive to both benomyl and thiobendazole, but the COL-1 group could be distinguished as slightly more tolerant than the COL-2 group and the Connecticut isolates. These assays provided persuasive evidence that the isolates from Connecticut belong to COL-2 group. The introduction of this homogenous pathogen population in Connecticut is likely due to the importation of infested seeds.
\end{abstract}

Lupines (Lupinus spp.) are grown in North America as ornamentals and for forage (2). The Russell hybrids (Lupinus spp. 'Russell Hybrid') have brilliant flowering racemes and are among the most popular ornamental lupines grown in the United States. In 1996, anthracnose was observed in Russell hybrid lupines in several nurseries in Connecticut. When young plants were infected, one or two stems wilted, shriveled, and died. Stems of older plants were bent, and the pathogen sporulated in the crook. Leaf spots also were observed. In severe cases, the crowns became rotten and discolored. Isolation from the affected tissues consistently yielded a Colletotrichum sp.

The taxonomy of Colletotrichum isolates from lupine has not been resolved. The first outbreak of anthracnose on lupines occurred in Florida in 1939 and was attributed to $C$. gloeosporioides (25) using the taxonomy of Sutton (23). However, Sreenivasaprasad et al. (22) advocated labeling lupine isolates as $C$. acutatum

Corresponding author: W. Elmer

E-mail: wade.elmer@po.state.ct.us.

Accepted for publication 21 October 2000.

Publication no. D-2000-1127-03R

(C) 2001 The American Phytopathological Society sensu lacto (Simmonds and Simmonds) after reporting close homology in the nucleotide sequence of the rDNA spacer 1 region between test isolates and referenced isolates of $C$. acutatum. Yang and Sweetingham (27) analyzed and compared a global collection of isolates from species of Lupinus with known cultures of $C$. acutatum using random amplified polymorphic DNA (RAPD) profiles, vegetative compatibility, and colony morphology. Sufficient variation in RAPD profiles and spore and colony morphology was found between the lupine isolates and cultures of C. acutatum to support the traditional species designation of $C$. gloeosporioides as described by Sutton (23). However, Yang and Sweetingham (27) reported that lupine isolates of C. gloeosporioides could be divided into two distinct groups based on physiological and molecular tests. The majority of the isolates were classed as one vegetative compatibility group (VCG) and had the same RAPD profiles. Another, smaller group (COL-1) contained isolates from France and Quebec, Canada that formed another VCG and had different RAPD profiles than COL-2 isolates. Both COL-1 and COL-2 may represent distinct clonal populations. Lardner et al. (14) confirmed the findings of Yang and Sweetingham (27) but, using Sreenivasaprasad et al. (22) species criteria, designated the COL-2 COL-2 (27). These isolates belonged to and COL-1 groups from lupine as $C$. acutatum sensu lacto (Simmonds and Simmonds) group D and group E, respectively.

Anthracnose of lupine is seedborne (6) and occurs in most regions where forage lupines are grown. The disease of ornamental lupines in Connecticut was not observed before 1996. Observations from growers suggested that the benzimidazole fungicides did not suppress the disease, but it was not known if the pathogen was insensitive or if applications were made too late to affect disease development. The objective of this study was to determine the pathogenicity, vegetative compatibility, fungicide sensitivity, and RAPD profiles of C. gloeosporioides from ornamental lupines in Connecticut, and to determine whether the Connecticut population belongs to the COL-1 group, the COL-2 group, or a separate group.

\section{MATERIALS AND METHODS}

Origin of test isolates. Infected crown and stem tissue from symptomatic ornamental lupines (Lupinus spp. Russell Hybrid) in seven nurseries in Connecticut were collected. Pieces of infected tissue (5by-5-mm) were washed in tap water, disinfested in $10 \%$ household chlorine bleach $\left(\mathrm{NaClO}_{2}\right)$, rinsed in distilled water, and placed onto potato dextrose agar (PDA) plus streptomycin $(250 \mu \mathrm{g} / \mathrm{ml})$. Colonies that grew from the tissue were subcultured onto carnation leaf agar (CLA; 5) by transferring a single conidium as described by Burgess et al. (5) for the culture of Fusarium spp. Additional isolates from New Hampshire, New York, and Utah from ornamental lupines also were obtained. Isolates from Canada and France that belonged to COL-1 and isolates from Australia and France that belonged to COL-2 were included in the study. Two Connecticut isolates of $C$. gloeosporioides pathogenic on Euonymus spp. were included as benzimidazole-insensitive controls. All isolates were cultured on PDA for 7 to 10 days under cool white fluorescent light at room temperature. Colony, spore, and appressorial morphologies were determined. All isolates were grown on CLA medium and stored on silica gel as described by Windels et al. (26). These stored cultures were used for all assays.

Pathogenicity tests. All isolates from the United States were tested for patho- 
genicity on lupine (Lupinus spp. Russell Hybrid mix; Ball Seed Co., Chicago) seedlings. Seeds were soaked in water for 1 day, germinated in potting mix, and transplanted into 18-cell seedling trays for 1 month. Isolates were grown on potatocarrot agar (7) for 7 to 10 days under cool white fluorescent light at room temperature to promote sporulation. Conidia were washed from the agar with sterile distilled water and the concentration was adjusted to $10^{6}$ conidia/ml. Pathogenicity tests were conducted using a modification of the procedure of Reddy et al. (19). Using a hypodermic needle, $25 \mu \mathrm{l}$ of the conidial suspension were injected into the largest stem on the plant and the wound was wrapped with parafilm. Four to six replicate plants were inoculated per isolate in each test. Control plants received injections of sterile distilled water or a conidial suspension of nonpathogenic $F$. oxysporum to serve as a nonpathogen control. Plants were monitored for 2 weeks in the greenhouse. Test isolates were scored as virulent if the inoculated stem wilted and died. Reisolations from the stem lesion were done to confirm the presence of the test isolate. Each isolate was tested at least twice. Isolates from Canada, France, and Australia were previously shown to be pathogenic on lupine $(17,27)$.

Vegetative compatibility grouping. Procedures for conducting tests for vegetative compatibility have been described before $(21,27)$. Our procedure differed only in that chlorate resistant mutants were selected on KMM medium (minimal medium [4] plus $1.6 \mathrm{~g}$ of asparagine per liter) amended with $\mathrm{KClO}_{3}$ at $25 \mathrm{~g} /$ liter Complementary nitrate nonutilizing (nit) $\mathrm{mu}-$ tants were selected from all $C$. gloeosporioides isolates from lupine and paired. Isolates were scored as vegetatively compatible if their nit mutants formed heterokaryotic growth with nit mutants from another isolate. All isolates were tested for vegetative compatibility.

Fungicide tolerance. Three isolates from Connecticut were selected and compared with the three isolates in COL-1 and the three isolates in COL-2 for sensitivity to two benzimidazole fungicides, benomyl and thiobendazole. Cooled $\left(48^{\circ} \mathrm{C}\right)$ molten PDA was amended with each fungicide at $0.1,1.0,10.0$ and $100 \mu \mathrm{g}$ a.i./ml and seeded with colonized agar plugs $(0.4 \mathrm{~mm}$ in diameter) of each isolate. Nonamended PDA served as a control. Plates were held at $22^{\circ} \mathrm{C}$ in the dark. Radial growth was measured every 2 to 3 days for 9 days. There were three replicates per treatment, and the experiment was repeated once. Growth rates (centimeters per day) were computed from linear regression of radial growth versus time. The percent reduction in growth rate was calculated for each isolate at each fungicide concentration ([growth rate of control - growth rate at concentration $X]$ /growth rate of control). The percent reduction in growth rates was then plotted against the $\log$ concentration of each respective fungicide to produce significant linear fits with $r^{2}>0.80$. The slopes $(\beta)$ of these linear fits for each isolate-fungicide were compared using analysis of variance.

RAPD profiles. RAPD analyses were conducted as described by Yang and

Table 1. Host, isolates, and pathogenicity on Lupinus sp. and vegetative compatibility groups (VCGs) of Colletotrichum gloeosporioides used

\begin{tabular}{|c|c|c|c|c|c|}
\hline Host & $\begin{array}{l}\text { No. of isolates } \\
\text { (or strain) }\end{array}$ & Origin & Source $^{w}$ & Tests $^{x}$ & VCG $^{y}$ \\
\hline Lupinus sp. Russell Hybrid & 10 & CT Nursery A & a & + & 2 \\
\hline Lupinus sp. Russell Hybrid & 5 & CT Nursery B & a & + & 2 \\
\hline Lupinus sp. Russell Hybrid & 5 & CT Nursery C & $\mathrm{a}$ & + & 2 \\
\hline Lupinus sp. Russell Hybrid & 2 & CT Nursery D & $\mathrm{a}$ & + & 2 \\
\hline Lupinus sp. Russell Hybrid & 2 & CT Nursery E & $\mathrm{a}$ & + & 2 \\
\hline Lupinus sp. Russell Hybrid & 1 & CT Nursery F & a & + & 2 \\
\hline Lupinus sp. Russell Hybrid & 1 & CT Nursery G & a & + & 2 \\
\hline Lupinus sp. Russell Hybrid & 1 & New York & $\mathrm{b}$ & + & 2 \\
\hline Lupinus sp. Russell Hybrid & 1 & Utah & $\mathrm{c}$ & + & 2 \\
\hline Lupinus sp. Russell Hybrid & 1 & New Hampshire & $\mathrm{c}$ & + & 2 \\
\hline L. albus & $(96 \mathrm{~A} 4)$ & WA, Australia & $\mathrm{d}$ & $t^{\mathrm{z}}$ & 2 \\
\hline L. angustifolius & $(96 \mathrm{~A} 2)$ & WA, Australia & $\mathrm{d}$ & $t^{\mathrm{z}}$ & 2 \\
\hline L. albus & (G31) & France & $\mathrm{e}$ & $t^{\mathrm{Z}}$ & 2 \\
\hline L. albue & (G2) & France & $\mathrm{e}$ & $t^{\mathrm{z}}$ & 1 \\
\hline L. albus & (Can 1) & Quebec, Canada & $\mathrm{f}$ & $t^{\mathrm{Z}}$ & 1 \\
\hline L. albus & (Can 2) & Quebec, Canada & $\mathrm{f}$ & $t^{\mathrm{z}}$ & 1 \\
\hline L. albus & (TMC) & Quebec, Canada & $\mathrm{f}$ & $t^{\mathrm{z}}$ & 1 \\
\hline Euonymus sp. & (EC 1) & Connecticut & $\mathrm{g}$ & - & ? \\
\hline Euonymus sp. & (EC 3) & Connecticut & g & $-1+$ & ? \\
\hline
\end{tabular}

"w Sources: $\mathrm{a}=$ this study; $\mathrm{b}=$ Margie Daughtery, Cornell University, New York; c = Amy Rossman USDA ARS, Beltsville, MD; d = Huaan Yang (author); e = Jean Gondran, INRA, Versailles, France; $\mathrm{f}=$ Tim Paulitz, McGill University, Montreal, Canada; $\mathrm{g}=$ James LaMondia, Conn. Agric. Exp. Stn. Windsor, CT.

${ }^{x}$ Pathogenicity tests conducted on 1-month-old lupine seedlings, showing positive (+) or negative (-) results.

y VCG based on reaction of nitrate nonutilizing mutants; ? = unknown.

${ }^{\mathrm{z}}$ Isolates were shown to be virulent by the authors in other tests (27).
Sweetingham (27). Two isolates from COL-2 group, two from COL-1 group, eight test isolates from Connecticut, and two isolates from Euonymus spp. were compared. Each isolate was cultured in 20 $\mathrm{ml}$ of potato dextrose broth for 5 days in the dark at $25^{\circ} \mathrm{C}$. The mycelial mat was removed, blotted dry with sterile filter paper, and ground into powder in liquid nitrogen. Genomic DNA was extracted using the method of Raeder and Broda (18). Polymerase chain reaction (PCR) was performed in $25 \mu \mathrm{l}$ of reaction buffer containing 50 pmole of primer, $67 \mathrm{mM}$ Tris$\mathrm{HCl}(\mathrm{pH}$ 8.3), $0.2 \mathrm{mM}$ dNTP, $2.5 \mathrm{mM}$ $\mathrm{MgCl}_{2}, 2$ units of $\mathrm{Taq}$ polymerase (Biotech International, Perth, Western Australia), and approximately $25 \mathrm{ng}$ of DNA of each test isolate. Base primer OPC-5 (5'-GATGACCGCC-3'; Operon Technologies, Alameda, CA) was used in all DNA amplifications (27). The temperature profile for amplification was 1 cycle at $94^{\circ} \mathrm{C}$ for 2 min, 40 cycles at $94^{\circ} \mathrm{C}$ for $1 \mathrm{~min}, 35^{\circ} \mathrm{C}$ for $1 \mathrm{~min}$, and $72^{\circ} \mathrm{C}$ for $2 \mathrm{~min}$. The PCR products were separated on $6 \%$ polyacrylamide gels at $70 \mathrm{~V}$ for $7 \mathrm{~h}$. Gels were stained with ethidium bromide and bands were viewed and photographed under UV light.

\section{RESULTS}

Twenty-six isolates of $C$. gloeosporioides were isolated from diseased ornamental lupines (Lupinus spp. Russell Hybrids) in seven different nurseries in Connecticut from 1996 to 1998. Isolates were identified using the taxonomy of Sutton (23). Most cultures had a grayish pigment visible from the undersides of PDA dishes, but a few were light brown. Conidia were straight but obtruse at one end. Appressoria were rounded and irregular. Isolates from COL1 and COL-2 groups were morphologically indistinguishable from the U.S. isolates.

All lupine isolates collected from nurseries in Connecticut were pathogenic on lupine (Table 1). Stems usually wilted within 4 to 8 days after inoculation and then collapsed, usually breaking at the wound. The fungus was observed sporulating in the wound. One of the two isolates from Euonymus spp. caused the stem to wilt 10 days after inoculation and was considered to be slightly pathogenic. Noninoculated plants and plants injected with F. oxysporum remained green and turgid.

The Connecticut isolates of $C$. gloeosporioides and those from New Hampshire, New York, and Utah were all vegetatively compatible with each other and with the three isolates designated as COL-2 (Table 1). The three Canadian isolates were only compatible with each other. The two isolates of C. gloeosporioides from Euonymus could not be placed into any VCG and were not compatible with each other.

Both fungicides reduced the growth rate of the isolates from lupine (Table 2). The Connecticut isolates and the COL-2 iso- 
lates were very sensitive to the fungicides and their $\beta$ values did not differ from each other. However, the $\beta$ values of the COL-1 isolates differed from those of the COL-2 isolates and from the Connecticut isolates on media amended with both benomyl $(P=$ $0.006)$ and thiobendazole $(P=0.014)$. No differences in the $\beta$ values were detected within the COL-1 group, the COL-2 group, or the Connecticut isolates. The reaction of the two Euonymus isolates to the fungicides differed from each other. Isolate EC1 was more tolerant of benomyl than of thiobendazole; whereas, for EC3, the reverse was true.

RAPD analysis with primer OPC-5 yielded the same clusters found in the other assays (Fig. 1). The two COL-2 isolates
(96A2 and 92A4) from Australia had the same RAPD profiles as the eight Connecticut isolates. The two COL-1 isolates differed from the Connecticut isolates in several bands. The two $C$. gloeosporioides isolates from Euonymus spp. differed from all the lupine isolates and from each other.

\section{DISCUSSION}

The emergence of this disease in Connecticut coincides with the occurrence of anthracnose on different Lupinus spp. in Australia (15,24), Canada (17,19), England (20), New Zealand (8), and Poland (11). Each outbreak has been attributed to isolates that belong to either COL-1 or COL-2 groups (27). The isolates of C. gloeosporioides from ornamental lupines in

Table 2. Slopes $(\beta)$ of percent reduction in growth rates of isolates of Colletotrichum gloeosporioides plotted against log fungicide concentration ${ }^{\mathrm{y}}$

\begin{tabular}{|c|c|c|c|c|c|}
\hline \multirow[b]{2}{*}{ Host $^{z}$} & \multirow[b]{2}{*}{ Isolate } & \multicolumn{2}{|c|}{ Thiobendazole } & \multicolumn{2}{|c|}{ Benomyl } \\
\hline & & $\beta$ & s.e. $\beta$ & $\beta$ & s.e. $\beta$ \\
\hline \multicolumn{6}{|l|}{ CT isolates } \\
\hline Lupinus sp. RH & Cas1 & 0.142 & 0.03 & 0.162 & 0.01 \\
\hline Lupinus sp. RH & Cas9 & 0.157 & 0.01 & 0.134 & 0.02 \\
\hline Lupinus sp. RH & $\mathrm{Ga} 2$ & 0.152 & 0.01 & 0.112 & 0.02 \\
\hline Mean & $\ldots$ & $0.150 \mathrm{a}$ & $\ldots$ & $0.136 \mathrm{~b}$ & $\ldots$ \\
\hline \multicolumn{6}{|l|}{ COL-2 } \\
\hline L. albus & G31 & 0.143 & 0.02 & 0.127 & 0.02 \\
\hline L. albus & $96 \mathrm{~A} 4$ & 0.140 & 0.03 & 0.164 & 0.01 \\
\hline L. angustifolius & 96 A 2 & 0.145 & 0.02 & 0.145 & 0.02 \\
\hline Mean & $\ldots$ & $0.143 \mathrm{a}$ & $\ldots$ & $0.145 \mathrm{~b}$ & $\ldots$ \\
\hline \multicolumn{6}{|l|}{ COL-1 } \\
\hline L. albus & TMC & 0.071 & 0.01 & 0.08 & 0.01 \\
\hline L. albus & Can2 & 0.111 & 0.02 & 0.085 & 0.01 \\
\hline L. albus & Can1 & 0.096 & 0.01 & 0.085 & 0.03 \\
\hline Mean & $\ldots$ & $0.092 \mathrm{~b}$ & & $0.083 \mathrm{c}$ & \\
\hline Euonymus sp. & EC 1 & $0.106 \mathrm{~b}$ & 0.02 & $0.015 \mathrm{~d}$ & 0.004 \\
\hline Еuоnymus sp. & EC 3 & $0.053 \mathrm{c}$ & 0.01 & $0.211 \mathrm{a}$ & 0.022 \\
\hline
\end{tabular}

y Values represent the mean of six replicates (three replicates per experiment); $\beta=$ slopes of percent reduction in radial growth (centimeters per day; growth rate of nonamended plate growth rate on amended agar)/growth rate of control) versus $\log$ concentration of fungicide; s.e. $\beta=$ standard error of the slope; mean values followed by differing letters are significantly different according to Tukey's test at $P=0.05$; means represent the mean of 18 slopes.

${ }^{\mathrm{z}} \mathrm{CT}=$ Connecticut; $\mathrm{RH}=$ Russell Hybrid .

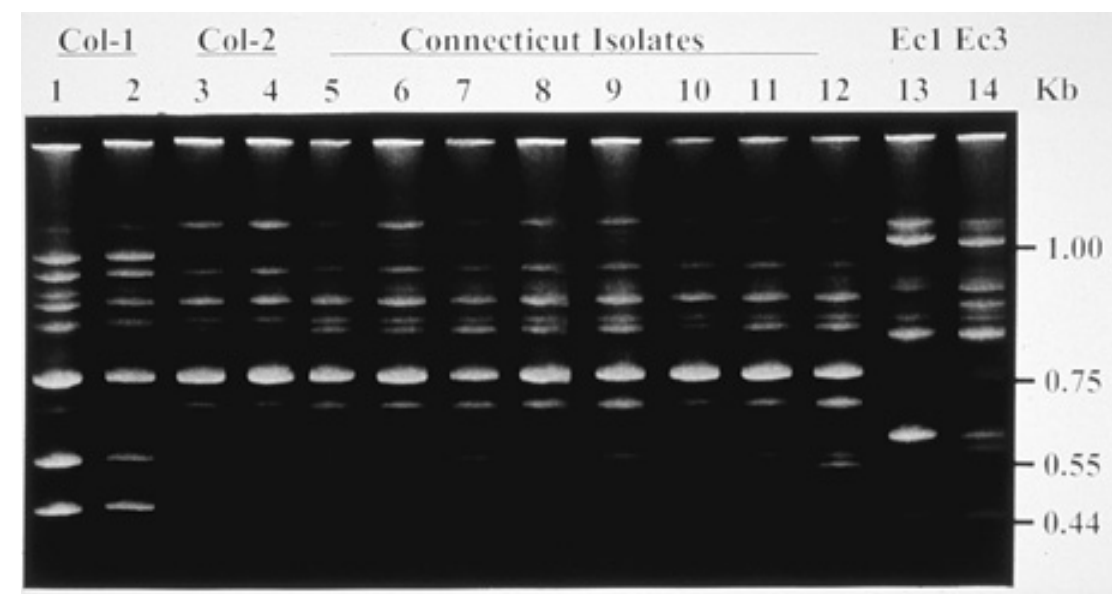

Fig. 1. Random amplified polymorphic DNA profiles for isolates of Colletotrichum gloeosporioides from Lupinus spp. (lanes 1 to 12) and Euonymus spp. (lanes 13 to 14) generated using polymerase chain reaction primer OPC-5 (5'-GATGACCGCC-3'). Lanes $1-2=$ COL-1 isolates, lanes 3-4 = COL-2 isolates, lanes 5-12 = Connecticut isolates. Lane $1=\mathrm{G} 2,2=\mathrm{TMC}, 3=96 \mathrm{~A} 2,4=92 \mathrm{~A} 4,5=$ $\operatorname{CAS} 1,6=\operatorname{CAS} 3,7=\operatorname{CAS} 4,8=\operatorname{CAS} 6,9=\operatorname{CAS} 7,10=\operatorname{CAS} 8,11=\operatorname{CAS} 9,12=\mathrm{GA} 2,13=$ $\mathrm{EC} 1$, and $14=\mathrm{EC} 3$.
Connecticut composed a homogenous population that did not differ in colony morphology, pathogenicity, vegetative compatibility, RAPD profiles, or tolerance to benzimidazole fungicides. Based on these assays, the Connecticut population could be assigned to the COL-2 group as characterized by Yang and Sweetingham (27). These findings support previous studies indicating that the emerging epidemic on lupines is caused by one of two clonal populations of $C$. gloeosporioides $(15,21,27)$. The population of $C$. gloeosporioides on lupines in Australia was also assigned to the COL-2 group (27). However, the outbreak of anthracnose on white lupine (L. albus) in Canada $(17,19)$ and France (27) was attributed to isolates in both the COL-1 and COL-2 groups (27, M. W. Sweetingham, unpublished data).

C. gloeosporioides represents a complex group of many related forms. Variation within this species has led many researchers to group populations into subgroups using morphological and physiological traits $(1,3,16)$. Most traits used to delineate these groups are linked with pathogenicity on a particular host. In fact, molecular, morphological, and physiological tests usually revealed a high degree of homogeneity among isolates of $C$. gloeosporioides from one host $(10,16)$, but a few exceptions have been demonstrated in which a high degree of heterogeneity as been observed (9). Two main groups exist on lupine. Both COL-1 and COL-2 groups are found in France and Canada but, in other places, only COL-2 has been found (27). The emergence of two distinct populations on one host is not uncommon and has been observed on citrus (16) and a legume, Stylosanthes spp. (12).

Yang and Sweetingham (27) reported a third group (COL-3) from Portugal that was slightly pathogenic on lupine but highly pathogenic on strawberry. Isolates in COL-3 had RAPD patterns and spore morphology similar to those of a typical strawberry isolate of $C$. acutatum; therefore, this group was classified as $C$. $a c u$ tatum. However, the lack of variation in the nucleotide sequence of the rDNA spacer 1 region led Sreenivasaprasad et al. (22) and Lardner et al. (14) to propose merging C. gloeosporioides isolates from lupine into $C$. acutatum. Yang and Sweetingham (27) argued that sufficient differences in morphology and variation in RAPD profiles remain between the species to maintain Sutton species designations. They also reported that the nucleotide sequence of rDNA spacer 1 region from authentic reference cultures of $C$. gloeosporioides and $C$. acutatum were not species specific (27).

The two Euonymus isolates not only differed from isolates in the COL-1 and COL2 groups, they also had considerable variation between them. This was evident in their RAPD profiles and in their reaction to 
benzimidazole fungicides. In general, isolates of $C$. gloeosporioides are reported to be sensitive to benomyl (10), but insensitivity can result from overexposure. Benzimidazole insensitivity has recently been detected in a Connecticut population of $C$. gloeosporioides from Euonymus spp. (13). Timely sprays of benzimidazole fungicides should be effective in suppressing this disease on lupine because the pathogen is still sensitive to them. The $\beta$ values for isolates in COL-1 group were significantly smaller than those in COL-2 groups or the Connecticut isolates; therefore, the COL-1 isolates may be slightly more tolerant of the fungicides than the other isolates from lupine. Liyanage et al. (16) also reported differences in benzimidazole sensitivity between two populations of C. gloeosporioides from citrus.

Shivas et al. (21) suspected that the COL-1 group might have been the prevalent group in the United States when the disease first appeared in 1939 and then spread to Europe and Canada on infested seed. This hypothesis has not been sufficiently tested due to the lack of available isolates from the United States. The current study provides strong evidence that the fungus causing the disease in Connecticut belongs to the COL-2 group of $C$. gloeosporioides. The rapid appearance of isolates in this group in so many locales implicate infested seed as the major vehicle for dissemination. Lindbeck et al. (15) in New South Wales, Australia were able to confirm that a seed lot of ornamental lupines from Europe was infested with COL-2 isolates. The isolates from Utah, New Hampshire, and New York were also assigned to the COL-2 group, which indicates that infested seed has probably been distributed nationally. Seed disinfestation procedures are needed to minimize the spread of this disease. The homogeneity of the isolates in COL-2 may allow the development of molecular probes to discriminate among pathogens and nonpathogens and aid in screening seed lots.

\section{ACKNOWLEDGMENTS}

We thank E. O'Dowd for technical assistance; and M. Daughtrey, T. Paulitz, L. Pundt, and A. Rossman for providing isolates or diseased plant material, and F. Ferrandino for assistance with Figure 1.

\section{LITERATURE CITED}

1. Agostini, J. P., Timmer, L. W., and Mitchell, D. J. 1992. Morphological and pathological characteristics of strains of Colletotrichum gloeosporioides from citrus Phytopathology 82:1377-1382.

2. Bailey, L. H., and Bailey, E. Z. 1976. Hortus Third: A Concise Dictionary of Plants Cultivated in the United States and Canada. MacMillan Publishing Co., New York.

3. Beever, R. E., Olsem, T. L., and Parkekes, S. I 1995. Vegetative compatibility groups in Colletotrichum gloeosporioides (Glomerella cingulata) from apple and other fruits Australas. Plant Pathol. 24:126-132.

4. Brooker, N. L. Leslie, J. F., and Dickmans, M. B. 1991. Nitrate nonutilizing mutants of Colletotrichum and their use in studies of vegetative compatibility. Phytopathology 81:672-677.

5. Burgess, L. W., Summerell, B. A., Bullock, S., Gott, K. P., and Backhouse, D. 1994. Laboratory Manual For Fusarium Research. 3rd ed. Fusarium Res. Lab. Dep. Crop Sci. Univ. Sydney, and The Royal Botanic Gardens, Sydney, NSW, Australia.

6. Decker, P. 1947. Anthracnose of blue lupine is seedborne. Plant Dis. Rep. 31:486.

7. Dhingra, O. D., and Sinclair, J. B. 1985. Basic Plant Pathology Methods. CRC Press, Inc., Boca Raton, FL.

8. Dick, M. A. 1994. Blight of Lupinus arboreus in New Zealand. N.Z. J. For. 24:51-68.

9. Freeman, S., Katan, T., and Shabi, E.1996. Characterization of Colletotrichum gloeosporioides isolates from avocado and almond fruits with molecular and pathogenicity tests. Appl. Environ. Microbiol. 62:1014-1020.

10. Freeman, S., Katan, T., and Shabi, E. 1998. Characterization of Colletotrichum species responsible for anthracnose disease of various fruit. Plant Dis. 82:596-605.

11. Frencel, I. M. 1998. Report on first detection of anthracnose (Colletotrichum gloeosporioides) on lupins in Poland. Plant Dis. 82:350.

12. He, C. A., Masel, A. M., Irwin J. A. G. Kelemu, S., and Manners, J. M 1995. Distribution and relationship of chromosome-specific and dispensable DNA sequences in diverse isolates of Colletotrichum gloeosporioides. Mycol. Res. 99:1325-1333.

13. LaMondia, J. A., 1998. Management of an- thracnose leaf spot and fungicide resistance in Euonymus. (Abstr.) Phytopathology 88:S31

14. Lardner, R., Johnston, P. R., Plummer K. M., and Pearson, M. N. 1999. Morphological and molecular analysis of Colletotrichum acutatum sensu lato. Mycol. Res. 103:275-285.

15. Lindbeck, K. D., Murray, G. M., Nikandrow, A., Priest, M., and Dominiak, B. C.1998. Survey for anthracnose caused by Colletotrichum gloeosporioides in crop lupins (Lupinus angustifolius, L. albus) and ornamental lupins (L. polyphyllus) in New South Wales. Australas. Plant Pathol. 27:259-262.

16. Liyanage, H. D., McMillan, T. J., and Kistler, H. C. 1992. Two genetically distinct populations of Colletotrichum gloeosporioides from citrus. Phytopathology 82:1371-1276.

17. Paulitz, T. C., Atlin G., and Gray, A. B. 1995. First report of Colletotrichum gloeosporioides on lupine in Canada. Plant Dis. 79:319

18. Raeder, U., and Broda, P. 1985. Rapid preparation of DNA from filamentous fungi. Lett. Appl. Microbiol. 1:17-20.

19. Reddy, M. V. B., Atlin, G., and Paulitz, T. C. 1996. Response of white lupin cultivars to Phoma and Colletotrichum gloeosporioides. Can J. Plant Pathol. 18:272-278.

20. Reed, P. J., Dickens, J. S. W., and O'Neil, T. M. 1996. Occurrence of anthracnose (Colletotrichum acutatum) on ornamental lupin in the United Kingdom. Plant Pathol. 45:245-248.

21. Shivas, R. G., McClements, J. L., and Sweetingham, M. L. 1998. Vegetative compatibility amongst isolates of Colletotrichum gloeosporioides causing lupin anthracnose. Australas. Plant Pathol. 27:269-273.

22. Sreenivasaprasad, S., Mills, P. R., and Brown, A. E. 1994. Nucleotide sequence of the rDNA spacer 1 enables identification of the isolates of Colletotrichum as C. acutatum. Mycol. Res. 98:186-188.

23. Sutton, B. C. 1980. The Coelomyces. Commonwealth Mycological Institute, Kew, UK.

24. Sweetingham, M. W., Cowling, W. A., Buirchell, B., Brown, A. G. P., and Shivas, R G. 1995. Anthracnose of lupins in Western Australia. Australas. Plant Pathol. 24:271

25. Weimer J. L. 1943. Anthracnose of lupins. Phytopathology 33:249-252.

26. Windels, C. E., Burnes, P. M., and Kommedahl, T. 1988. Five year preservation of Fusarium species on silica gel and soil. Phytopathology 78:107-109.

27. Yang, H. A., and Sweetingham, M. W. 1998 The taxonomy of Colletotrichum isolates associated with lupin anthracnose. Aust. J. Agric. Res. 49:1-11. 